\title{
Wave run-up on bermed coastal structures
}

Karthika Pillai ${ }^{\mathrm{a}}$, Amir Etemad-Shahidi ${ }^{*}$,c,d and Charles Lemckert ${ }^{\mathrm{e}, \mathrm{d}}$

${ }^{\mathrm{a}}$ Griffith School of Engineering and Built Environment, Griffith University, QLD, 4222, Australia

karthika.pillai@griffithuni.edu.au

${ }^{\mathrm{b}}$ Griffith School of Engineering and Built Environment, Griffith University, QLD, 4222, Australia

${ }^{\mathrm{c}}$ School of Engineering, Edith Cowan University, WA, 6027, Australia

${ }^{\mathrm{d}}$ Griffith Centre for Coastal Management, Griffith University, QLD, 4222, Australia

E-mail: a.etemadshahidi@griffith.edu.au

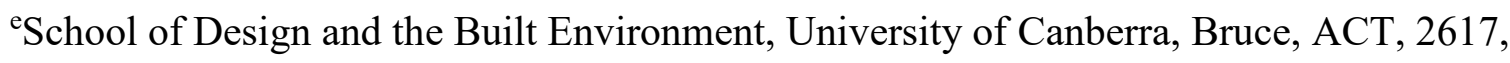
Australia

${ }^{\mathrm{d}}$ Griffith Centre for Coastal Management, Griffith University, QLD, 4222, Australia E-mail: Charles.Lemckert@,canberra.edu.au 


\begin{abstract}
Reliable estimation of wave run-up is required for the effective and efficient design of coastal structures when flooding or wave overtopping volumes are an important consideration in the design process. In this study, a unified formula for the wave run-up on bermed structures has been developed using collected and existing data. As data on berm breakwaters was highly limited, physical model tests were conducted and the run-up was measured. Conventional governing parameters and influencing factors were then used to predict the dimensionless run-up level with $2 \%$ exceedance probability. The developed formula includes the effect of water depth which is required in understanding the influence of sea level rise and consequent changes of wave height to water depth ratio on the future hydraulic performance of the structures. The accuracy measures such as RMSE and Bias indicated that the developed formula is more accurate than the existing formulas. Additionally, the new formula was validated using field measurements and its superiority was observed when compared to the existing prediction formulas. Finally, the new design formula incorporating the partial safety factor was introduced as a design tool for engineers.
\end{abstract}

Keywords: Wave run-up; Bermed structures; Laboratory experiments; Surf similarity; Prediction formula; Field measurements 


\section{Introduction}

Wave run-up height $\left(R_{u}\right)$ is an important hydraulic parameter in the design of coastal structures such as dikes, revetments and breakwaters [1]. $R_{u}$ is defined as the maximum distance travelled by a wave up a slope and is measured vertically from the still water level (SWL) during the wave action (Fig. 1). Knowledge of $R_{u}$ is required for the safety assessment of coastal structures and for estimating the number of waves that will reach the crest of the structure and overtop [2]. In addition, information on run-up is utilized to estimate the damage to the inner structure slope [3]. Thus, a reliable prediction of run-up is essential to develop a safe design of the coastal structure. Importantly, the prediction tool must be robust and should include the influence of water depth on wave run-up as this may change over time as the result of sea level rise or unpredicted coastal subsidence.

Estimation of run-up is more relevant to smooth sloped structures and structures situated on shore (such as seawalls) and is often less important for rubble mound breakwaters as their crest levels are often determined from overtopping rates. Recently Van der Meer et al. [2] has provided allowable values of mean overtopping rates as well as maximum overtopping volumes for different cases. Pillai et al. ([4], [5]) reviewed the existing approaches for the estimation of mean overtopping rates and developed a more accurate formula for it. To our knowledge, no study has been conducted on the estimation of max overtopping volume and runup at berm structures. The run-up prediction is essential to estimate the number of waves that may reach the crest and eventually lead to wave overtopping [2]. Additionally, it is required to determine the maximum overtopping volume of bermed structures. One of the earliest formulas to estimate the maximum run-up $\left(R_{u m}\right)$ on bermed revetments was suggested by Ahrens and Ward [6] as:

$$
R_{* m}=\frac{R_{u m}}{H_{m 0}}=\exp \left(0.695-11.269 \frac{H_{m 0}}{L_{0 p}}-0.158 B^{\prime}\right)
$$


where $H_{m 0}$ is the significant wave height, $L_{0 p}$ is the peak wave length and $B^{\prime}$ is a berm width factor [6] which is defined as:

$B^{\prime}=\frac{B}{\sqrt{H_{m 0} L_{0 p}}} \frac{h_{b t}}{h}$

Here, $B$ is the berm width, $h_{b t}$ is the height of the berm above the toe of the structure and $h$ is the water depth at the toe of the structure. It should be mentioned that the berm levels tested by Ahrens and Ward [6] were all submerged and therefore the effect of the berm emergence was not investigated. Noting that most of recent formulas for runup are given for 2\% exceedance probability and Ahrens and Ward [7] experiments were conducted on slopes with two layers of rock, Eq. (1) can be modified to:

$R_{*}=\frac{R_{u 2 \%}}{H_{m 0}}=0.79 R_{* m}=1.97 \gamma_{f} \exp \left(0.695-11.269 \frac{H_{m 0}}{L_{0 p}}-0.158 B\right)$

The conversion factor has been estimated by considering a roughness factor $\left(\gamma_{f}\right)$ of 0.4 for experiments with two layers of armour [2] and a $R_{u 2 \%}$ to $R_{u m}$ ratio of 0.79 obtained by measurements of Van der Meer [8].

Recently, Van der Meer et al. [2] suggested a power formula to estimate the dimensionless run-up as:

$R_{*}=\frac{R_{u 2 \%}}{H_{m 0}}=1.65 \gamma_{b} \gamma_{f} \gamma_{\beta} \xi_{m-1,0}$

With a maximum of

$$
\left\{\begin{array}{cc}
1.0 \gamma_{f} \gamma_{\beta}\left(4-\frac{1.5}{\sqrt{\gamma_{b} \xi_{m-1,0}}}\right)<3 & \text { for dikes } \\
1.0 \gamma_{\text {fsurging }} \gamma_{\beta}\left(4-\frac{1.5}{\sqrt{\gamma_{b} \xi_{m-1,0}}}\right)<2 & \text { for rubble mounds }
\end{array}\right.
$$

where 
$\xi_{m-1,0}=\frac{\tan \alpha_{a v}}{\sqrt{s_{m-1,0}}}$

$\tan \alpha_{a v}$ is the average slope defined as:

$\tan \alpha_{a v}=\left\{\begin{array}{cc}\frac{3 H_{m 0}}{L_{s}-B} & 1^{\text {st }} \text { estimate } \\ \frac{1.5 H_{m 0}+R_{u 2 \%(\text { Ist estimate })}}{L_{s}-B} & 2^{\text {nd }} \text { estimate }\end{array}\right.$

$L_{s}=B+\left[\left(1.5 H_{m 0}+h_{b}\right) \cot \alpha_{u}\right]+\left[\left(1.5 H_{m 0}-h_{b}\right) \cot \alpha_{d}\right]$

Here, $\cot \alpha_{u}$ and $\cot \alpha_{d}$ represent the slopes above and below the berm, respectively (Fig. 1). $h_{b}$ represents the depth of still water level above the berm and is positive for submerged berms. $L_{s}$ is the horizontal length between two points on slope, $R_{u 2 \%}$ above and $1.5 H_{m 0}$ below the SWL. Van der Meer et al. [2] suggests an iterative solution to determine $\tan \alpha_{a v}$ since $R_{u 2 \%}$ is initially unknown. The drawback of the iterative calculation is that the reliability of the estimated $R_{u 2} \%$ depends on the accuracy of the first estimation of $R_{u 2} \%$.

The wave steepness, $s_{m-1,0}$ is given as:

$S_{m-1,0}=\frac{2 \pi H_{m 0}}{g T_{m-1,0}^{2}}$

where $g$ is the acceleration due to gravity, $T_{m-1,0}$ is the mean energy wave period or spectral wave period. It should be mentioned that Van der Meer et al. [2] has provided a similar formula for estimating the $R_{u 2 \%}$ at dikes. However, the $\gamma_{f \text { surging }}$ in Eq. (5) has been replaced with $\gamma_{f}$.

Influence factors were proposed to take into account the effects of roughness $\left(\gamma_{f}\right)$. A $\gamma_{f}$ of 0.4 was suggested for rubble mound structures with two layers of rock over a permeable core. However, for maximum run-up of surging waves, $\gamma_{f \text { surging }}$ was suggested as:

$\gamma_{\text {fsurging }}=\gamma_{f}+\frac{\left(\xi_{m-1,0^{-1.8}}\right) \times\left(1-\gamma_{f}\right)}{8.2}$ for $1.8 \leq \xi_{m-1,0} \leq 10$ 
It is worth mentioning that the same formula with different maximum values is suggested by Van der Meer et al. [2] for dikes and rubble mounds. The main difference is introducing $\gamma_{f \text { surging }}$ in Eq. (4) for armoured rubble mounds and slopes which replaces $\gamma_{f}$ when $\xi_{m-1,0}>1.8$, and hence increases the maximum value of $R *$ for surging and collapsing waves.

The influence factor for oblique wave incidence $\left(\gamma_{\beta}\right)$ was considered as:

$\gamma_{\beta}=\begin{array}{cc}1-0.0063|\beta| & 0 \leq \beta \leq 80^{\circ} \\ 0.496 & |\beta|>80^{\circ}\end{array}$

where $\beta$ is the angle of wave incidence. For bermed structures, Van der Meer et al. [2] suggested the following influence factor:

$\gamma_{b}=1-r_{B}\left(1-r_{h b}\right) \geq 0.6$

$r_{B}=\frac{B}{L_{\text {berm }}}$

where $L_{b e r m}$ is the horizontal length between two points on slope, $1.0 H_{m 0}$ above and $1.0 H_{m 0}$ below the middle of the berm.

$r_{h b}=\left\{\begin{array}{cc}0.5-0.5 \cos \left(\pi \frac{h_{b}}{R_{u 2 \%}}\right) & \text { berm above SWL } \\ 0.5-0.5 \cos \left(\pi \frac{h_{b}}{2 H_{m 0}}\right) & \text { berm below SWL } \\ 1 & \text { berm lying outside the area of influence }\end{array}\right.$

It should be noted that similar to the estimation of average slope, $R_{u 2 \%}$ needs to be estimated first for emerged berms.

The influence factor for shallow foreshores was not included explicitly in Van der Meer et al. [2] mainly because $T_{m-1,0}$ was used in the formulations. However, Van der Meer and Janssen [9] suggested the following formulation for $\gamma_{h}$. 
$\gamma_{h}=\left\{\begin{array}{cc}1-0.03\left(4-\frac{h}{H_{m 0}}\right)^{2} & \text { for } \frac{h}{H_{m 0}}<4 \\ 1 & \text { for } \frac{h}{H_{m 0}} \geq 4\end{array}\right.$

The formula to estimate run-up for berm structures has been developed mostly based on data from smooth dike studies [10]. Hence, the approach used for composite dikes is used for these structures [2]. However, the response of a rubble mound berm could be different from that of a smooth bermed slope ([11], [2]).

The main objectives of this study are to investigate run-up on bermed structures and develop a unified prediction formula based on a database which includes bermed dikes and berm breakwaters. Hence, first, small-scale experiments were conducted to record the run-up on berm breakwaters. Then, using the M5`algorithm (e.g. [12]), a design formula was developed for bermed structures. The performance of the developed formula was compared with those of the existing prediction formulas for the combined data sets of bermed breakwaters and dikes. Moreover, the developed formula was validated using measurements at prototype berm structure.

\section{Lab Experiments and existing data}

As discussed above, hardly any measurement of run-up on bermed rubble mound structures exists. Hence, laboratory experiments were undertaken in this study on berm breakwaters as the first part of this research. The experiments were conducted in the $18 \mathrm{~m}$ long $\times 0.80 \mathrm{~m}$ deep $\times 0.45 \mathrm{~m}$ wide wave flume in the hydraulics laboratory of Griffith University, Australia. The piston wave maker installed in the flume is able to produce both regular and irregular waves and is equipped with an active wave absorption system. Irregular waves with a JONSWAP spectrum and a peak enhancement factor $(\gamma)$ of 3.3 were used for all 
tests. The tests were carried out on different rubble mound berm breakwater cross sections with a cot $\alpha$ of 1.50 above and below the berm (Fig. 2a). The model had a core with a nominal diameter $\left(D_{n 50}\right)$ of $0.021 \mathrm{~m}$ and $D_{n 85} / D_{n 15}$ of 2 , while the primary armour had a $D_{n 50}$ of 0.032 $\mathrm{m}$.

The free surface of the water in the flume was measured and the wave parameters were estimated using three capacitance wave gauges placed near the toe of the structure (Fig. 2b). The gauges were placed at distances of $X_{12}=0.50 \mathrm{~m}$ and $X_{13}=1.30 \mathrm{~m}$ where $X_{12}$ and $X_{13}$ are the distances of the second and third gauges from the first, respectively. Incident and reflected waves were separated using the method of three fixed probes [13]. Experiments were performed by varying the SWL, $h_{b}$ and the peak wave steepness $\left(s_{m-1,0}\right)$. Wave run-ups were measured using images collected from digital video cameras for approximately 1000 waves for each test condition. A scaled ruler was fixed on the front slope above the berm to increase the accuracy of the run-up estimates. The video of each test case was individually analysed frame by frame and the top $2 \%$ value of $R_{u}$ was reported as $R_{u 2 \%}$. The ranges of tested parameters are given in Table 1.

In addition, to have a more comprehensive data base, the smooth berm dataset was obtained from Van der Meer and De Waal [10]. The ranges of their parameters are summarised in Table 1. It can be seen from the table that rather wide berms with gentle smooth slopes were tested in their experimental program. However, rubble mound breakwaters in general have steeper slopes [2].

\section{Results and discussion}


Fig. 3a shows the scatter diagram of measured $\left(R *_{\text {meas }}\right)$ and estimated run-ups $\left(R *_{e s t}\right)$ using the modified Ahrens and Ward [6] formula. The runup data collected in this study is slightly underestimated by this formula, specially at high values of $R *_{m e a s}$, which could be due to the subjectivity in the run-up variable from visual observations ([6], [7]). However, it is interesting to note that all Van der Meer and De Waal [10] data points are overestimated by the modified Ahrens and Ward [6] formula. Fig. 3b presents the performance of the Van der Meer et al. [2] formula. It shows that there is an overestimation for the $R *_{\text {meas }}>2.0$ for the Van der Meer and De Waal [10] data. The run-up measurements of this study are also overestimated. This could be due to the linear relationship between $R *$ and $\xi_{m-1,0}$. Interestingly, this formula performs better for $R *_{\text {meas }}$ between 1.5 and 2.0.

To develop a new prediction model, seventy percent of the data, detailed in Table 1, was used as the training data and the remaining ones were used for testing the model. Dimensional analysis and M5 model tree technique [14] of WEKA software (see details in Appendix A) was used to develop a prediction formula to estimate the $R *$ (output). The governing variables such as $\xi_{m-1,0}, \gamma_{b}$ were used as inputs. $\gamma_{b}$ was calculated using Eq. (12). However, the $r_{h b}$ was obtained from Eq. (14) by replacing $R_{u 2} \%$ with $1.5 H_{m 0}$. Also, $\xi_{m-1,0}$ was obtained from Eq. (6), using the first estimate of $\tan \alpha_{a v}$ in Eq. (7). Hence it does not need any iteration or second estimation. $\gamma_{f}$ and $\gamma_{\beta}$ were assumed as 0.4 and 1.0 (head on waves), respectively [2]. Table 2 summarises the ranges of the used parameters.

Different functional forms and governing dimensionless parameters were utilised and the optimum formula was obtained as:

$R_{*}=\frac{R_{u 2 \%}}{H_{m 0}}=7.7 \gamma_{b} \gamma_{h} \gamma_{f} \gamma_{\beta}\left[1-\exp \left(-0.78 \xi_{m-1,0}\right)\right]$

With a maximum of 
$\left\{\begin{array}{cc}1.0 \gamma_{f} \gamma_{\beta}\left(3.15-\frac{1.5}{\gamma_{b} \xi_{m-1,0}}\right) & \text { for impermeable dikes } \\ 1.0 \gamma_{\text {surging }} \gamma_{\beta}\left(3.15-\frac{1.5}{\gamma_{b} \xi_{m-1,0}}\right) & \text { for rubble mounds }\end{array}\right.$

As seen, compared to Van der Meer et al. [2] formulas, a unified exponential formula which includes the water depth effect has been developed. As before, the surf similarity parameter is the most influential parameter in the estimation of run-up. This parameter includes the influence of $\tan \alpha, H_{m 0}$ and $T_{m-1,0}$ and its physical significance is well known, and the exponential functional form of the developed formula is justifiable since the sensitivity of $R *$ to $\xi_{m-1,0}$ decreases for surging waves ([15], [2]). The effects of other parameters, such as berm width and height, water depth and friction, are also considered in the developed formula. Eq. (16) includes the effect of water depth which is required in predicting the influence of sea level rise and consequent changes of wave height to water depth ratio on the future hydraulic performance.

Fig. 3c compares the $R *_{\text {meas }}$ against the $R *_{\text {est }}$ using the Eq. (16). It can be seen from the figure that the scatter is reduced, and the data points are closer to the optimal line, when compared to Figs. $3 \mathrm{a}$ and $3 \mathrm{~b}$. In addition, higher values of $R *^{*}$ meas $(>2)$ are better estimated by the developed formula. Furthermore, the performances of different formulas were quantitatively compared using the following accuracy measures:

$$
\begin{aligned}
& R M S E=\sqrt{\frac{1}{n} \sum_{i=1}^{i=n}\left(R_{*_{\text {est }}}-R_{*_{\text {meas }}}\right)^{2}} \\
& D R=\frac{1}{n} \sum_{i=1}^{i=n}\left(\frac{R_{*_{\text {est }}}}{R_{*_{\text {meas }}}}\right) \\
& \text { Bias }=\frac{1}{n} \sum_{i=1}^{i=n}\left(R_{*_{\text {est }}}-R_{*_{\text {meas }}}\right)
\end{aligned}
$$


where $n$ denotes the number of measurements. Table 3 summarises the performances of the different prediction formulas. The $D R$ value of the modified Ahrens and Ward [6] formula is greater than 1, indicating overestimation (as is presented in Fig.3a). RMSE, DR and Bias of the new formula are improved, even for the test data, when compared to the Van der Meer et al. [2] formula.

Due to the complex nature of the run-up process, the estimated run-up using the developed formula has uncertainties. In order to consider these uncertainties, the semi-probabilistic approach, with a partial safety factor [2], was considered and the formula was modified as follows:

$R_{*}=\frac{R_{u 2 \%}}{H_{m 0}}=7.7(1+0.24 N) \gamma_{b} \gamma_{h} \gamma_{f} \gamma_{\beta}\left[1-\exp \left(-0.78 \xi_{m-1,0}\right)\right]$

With a maximum of

$\left\{\begin{array}{cc}(1+0.24 N) \gamma_{f} \gamma_{\beta}\left(3.15-\frac{1.5}{\gamma_{b} \xi_{m-1,0}}\right) & \text { for impermeable dikes } \\ (1+0.24 N) \gamma_{\text {fsurging }} \gamma_{\beta}\left(3.15-\frac{1.5}{\gamma_{b} \xi_{m-1,0}}\right) & \text { for rubble mounds }\end{array}\right.$

Assuming a Gaussian residual distribution, values of $N$ can be obtained from Table 4. For example, when the acceptable risk is $2 \%$, an $N$ value of 2.05 needs to be used. One of the limitations of Eq. (16) is that it is developed from experimental data with head on waves. Hence, the estimation of $\gamma_{\beta}$ suggested by Van der Meer et al. [2] is suggested. The effects of wind and currents are not considered, and they can be modelled as influencing factors as suitable data becomes available.

\section{Application to the field data}


Results from applying different formulas are compared with the field measurements on Petten Sea defence in The Netherlands [16]. It should be mentioned that the local depth contours are nearly parallel to the coast and therefore the wave obliquity is negligible. The dike has a $14 \mathrm{~m}$ wide berm and upper and lower smooth slopes of 1:3 and 1:4.5, respectively. In the field, run-up measurements were obtained in the upper slope using step gauges. The average wave height was $2.8 \mathrm{~m}$ and $\xi_{m-1,0}$ varied from 1.91 to 2.56 (Table 5). Fig. 4 compares the estimated dimensionless run-up rates with those measured in the field. Even though $3 \mathrm{D}$ field measurements and $2 \mathrm{D}$ lab experiments could produce different results, this comparison can give some insight about the performance of different formulas, especially for head on wave condition. It can be seen that the measurements are mostly overestimated by the Van der Meer et al. [2] and modified Ahrens and Ward [6] formulas. Results obtained from the small scale experiments (Fig. 3) also show that for cases with high values of $R *(1.8<R *$ ) the formula of Van der Meer et al. [2] generally overestimates the observed run up levels by about $25 \%$. The overestimation is not likely due to the wave directionality since the reported waves were normal to the coast [16]. It is plausible that the overestimation is due to the inherent monotonic relationship between $R^{*}$ and $\xi_{m-1,0}$ in their formula which does not exist in other formulas.

The performance of different prediction formulas in the field are quantitatively compared in Table 5. As seen, the developed formula performs well for the field data with improved $R M S E$ and $D R$ compared to those of the existing prediction formulas. It is not surprising that the performances of all formulas are inferior in the field mainly due to modelling and scaling effects ([17], [18]).

In order to help practicing engineers, an example using design condition of Sirevag berm breakwater is given in Appendix B and the results are compared with those of other formulas. 


\section{Summary and Conclusion}

In this study, a unified prediction formula for the bermed slope structures was developed for bermed dikes and berm breakwaters. It was found that the existing measured run-up data on berm breakwaters, for model development and validation purposes, was highly limited and therefore physical model tests were conducted on different berm breakwater cross sections to help correct this deficiency.

The dominant input parameter in the developed model is the surf similarity parameter while the effects of berm, roughness, and water depth were influencing factors. The formula was validated using the measured run-up rates from prototype dike structure at Petten Sea defence in The Netherlands. It was shown that the introduced formula is more precise than the previous ones in estimating the full-scale run-up. The model also considers uncertainties to make it an appropriate design tool for engineers.

\section{Acknowledgements}

Mr. Mohit Saily and Mr. Son Pham are highly appreciated for their involvement in the data collection and processing. The University of Waikato is gratefully acknowledged for providing the WEKA software. In addition, the staff of the Hydraulics Laboratory at Griffith University are acknowledged for their contribution to the physical model tests. 


\section{List of symbols}

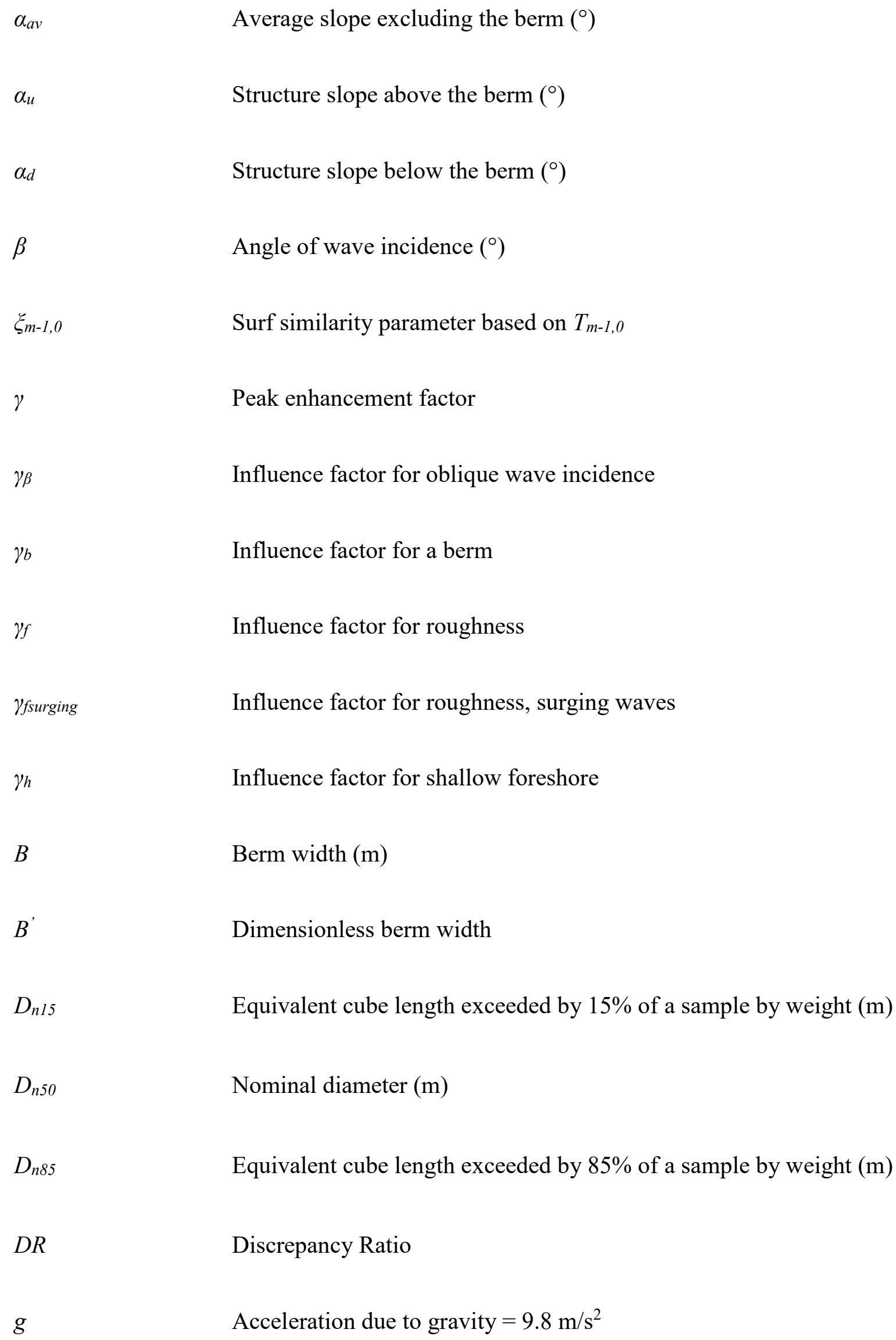


Water depth (m)

$h_{b}$

Berm level above the still water level ( $-h_{b}$ for emerged berm) (m)

$h_{b t}$

Height of the berm above the toe of the structure (m)

$H_{m 0}$

Significant wave height from spectral analysis (m)

$L_{b e r m}$

Horizontal length between two points on slope, $1.0 H_{m 0}$ above and 1.0

$H_{m 0}$ below middle of the berm (m)

$L_{m-1,0}$

Deep water peak wave length using $T_{m-1,0}(\mathrm{~m})$

$L_{0 p}$

Deep water peak wave length (m)

$L_{S}$

Horizontal length between two points on slope, $R_{u 2} \%$ above and 1.5

$H_{m 0}$ below SWL (m)

$n$

Number of measurements

$N$

Coefficient for various levels of acceptable risk

$R *$

Dimensionless $R_{u 2 \%}\left(R_{u 2 \%} / H_{m 0}\right)$

$R * e s t$

Estimated dimensionless $R_{u 2} \%$

$R *_{m}$

Maximum dimensionless runup $\left(R_{\max } / H_{m 0}\right)$

$R *^{*}$ meas

Measured dimensionless $R_{u 2 \%}$

$r_{B}$

Reduction factor for size of berm

$R_{c}$

Crest freeboard of structure (m)

Reduction factor for level of berm with respect to SWL 
$R_{u}$

$R_{u 2 \%}$

$R_{u m}$

$R_{u 2 \% \_ \text {meas }}$

$S_{m-1,0}$

$S W L$

$T_{m-1,0}$

$X_{12}$

$X_{13}$
Run-up height, measured vertical with respect to the SWL (m)

Run-up height exceeded by $2 \%$ of the incident waves (m)

Maximum run-up height of all waves in a sea state (m)

Measured run-up height exceeded by $2 \%$ of the incident waves (m)

Wave steepness based on $T_{m-1,0},=H_{m 0} / L_{m-1,0}=2 \pi H_{m 0} /\left(g T_{m-1,0^{2}}\right)$

Still Water level (m)

Spectral wave period defined by $m_{-1} / m_{0}(\mathrm{~s})$

Distance between first and second gauge (m)

Distance between first and third gauge (m) 


\section{List of tables}

Table 1. Ranges of parameters in the existing and new datasets of bermed slopes

Table 2. Ranges of input-output parameters in the training and test data

Table 3. Accuracy measures of different prediction models

Table 4. $N$ values for various levels of acceptable risk [19]

Table 5. Comparison of $R *_{m e a s u r e d}$ with $R *_{\text {estimated }}$ using different prediction formulas, field data 
Table 1. Ranges of parameters in the existing and new datasets of bermed slopes

\begin{tabular}{|c|c|c|c|}
\hline Parameter & Van der Meer and De Waal [10] & This study & Total \\
\hline$R_{c}(\mathrm{~m})$ & - & $0.08-0.18$ & $0.08-0.18$ \\
\hline$B(\mathrm{~m})$ & $0.40-1.00$ & $0.25-0.45$ & $0.25-1.00$ \\
\hline$h_{b}(\mathrm{~m})$ & $-0.08-0.16$ & $-0.08-0.05$ & $-0.08-0.16$ \\
\hline$h(\mathrm{~m})$ & $0.52-0.76$ & $0.38-0.48$ & $0.38-0.76$ \\
\hline$H_{m 0}(\mathrm{~m})$ & $0.10-0.20$ & $0.06-0.16$ & $0.06-0.20$ \\
\hline$T_{m-1,0}(\mathrm{~s})$ & $1.49-2.56$ & $1.00-1.76$ & $1.00-2.56$ \\
\hline $\cot \alpha$ & $3.00-4.00$ & 1.50 & $1.50-4.00$ \\
\hline$s_{m-1,0}$ & $0.01-0.05$ & $0.02-0.07$ & $0.01-0.07$ \\
\hline$\xi_{m-1,0}$ & $0.99-4.46$ & $2.15-5.73$ & $0.99-5.73$ \\
\hline$\gamma_{b}$ & $0.60-0.82$ & $0.61-0.78$ & $0.60-0.82$ \\
\hline$\gamma_{h}$ & 1.00 & $0.77-1.00$ & $0.77-1.00$ \\
\hline$R_{u 2 \%}(\mathrm{~m})$ & $0.15-0.39$ & $0.06-0.17$ & $0.06-0.39$ \\
\hline$R_{u 2 \%} / H_{m 0}$ & $1.21-2.96$ & $0.73-1.82$ & $0.73-2.96$ \\
\hline Structure type & Bermed dike & Berm breakwater & Both \\
\hline Number of data & 75 & 59 & 134 \\
\hline
\end{tabular}


Table 2. Ranges of input-output parameters in the berm structures training and test data

\begin{tabular}{ccc}
\hline Parameter & Train data & Test data \\
\hline $\tan \alpha_{\text {average }}$ & $0.22-0.78$ & $0.26-0.66$ \\
\hline$s_{m-1,0}$ & $0.01-0.07$ & $0.02-0.05$ \\
\hline$\gamma_{b}$ & $0.60-0.90$ & $0.61-0.81$ \\
\hline$\gamma_{h}$ & $0.75-1.00$ & $0.92-1.00$ \\
\hline$\gamma_{f}$ & $0.40,1.00$ & $0.40,1.00$ \\
\hline$\gamma_{f \text { surging }}$ & $0.43-0.69$ & $0.49-0.54$ \\
\hline$\xi_{m-1,0}$ & $0.99-5.73$ & $1.32-3.72$ \\
\hline$R_{*}$ & $0.73-2.96$ & $0.81-1.81$ \\
\hline Total & 95 & 39 \\
\hline
\end{tabular}


Table 3. Accuracy measures of different prediction models

\begin{tabular}{cccccccccc}
\hline & \multicolumn{8}{c}{ Formula } \\
\cline { 2 - 10 } Data & \multicolumn{10}{c}{ Modified Ahrens and Ward [6] } & \multicolumn{2}{c}{ Van der Meer et al. [2] } & & This study \\
\cline { 2 - 10 } & RMSE & DR & Bias & RMSE & DR & Bias & RMSE & DR & Bias \\
\hline Test & 0.63 & 1.25 & 0.41 & 0.28 & 1.19 & 0.22 & 0.20 & 1.15 & 0.15 \\
\hline All & 0.62 & 1.20 & 0.68 & 0.36 & 1.16 & 0.24 & 0.21 & 1.06 & 0.03 \\
\hline
\end{tabular}


Table 4. $N$ values for various levels of acceptable risk [19]

\begin{tabular}{cc}
\hline Acceptable risk (\%) & $N$ \\
\hline 2 & 2.05 \\
\hline 5 & 1.65 \\
\hline 10 & 1.28 \\
\hline 33 & 0.44 \\
\hline 50 & 0.00 \\
\hline
\end{tabular}


Table 5. Comparison of $R *_{\text {meas }}$ with $R *_{\text {est }}$ using different prediction formulas, field data

\begin{tabular}{|c|c|c|c|c|c|}
\hline \multirow{2}{*}{$\begin{array}{l}\text { Storm } \\
\text { number }\end{array}$} & \multirow[b]{2}{*}{$\xi_{m-1,0}$} & \multirow[b]{2}{*}{$R *$ meas } & \multicolumn{3}{|c|}{ Estimations } \\
\hline & & & $\begin{array}{c}\text { Modified Ahrens and } \\
\text { Ward [6] }\end{array}$ & $\begin{array}{c}\text { Van der Meer et al. } \\
\text { [2] }\end{array}$ & This study \\
\hline 1.01 & 1.91 & 2.12 & 2.59 & 2.59 & 1.91 \\
\hline 1.02 & 1.94 & 1.99 & 2.58 & 2.61 & 1.94 \\
\hline 1.03 & 2.44 & 2.17 & 3.03 & 2.70 & 2.04 \\
\hline 1.04 & 2.56 & 1.99 & 2.50 & 2.75 & 2.11 \\
\hline 1.05 & 2.28 & 1.86 & 2.63 & 2.70 & 2.04 \\
\hline 1.06 & 2.06 & 2.04 & 2.14 & 2.64 & 1.97 \\
\hline & $R M S E$ & & 0.60 & 0.65 & 0.14 \\
\hline & $D R$ & & 1.27 & 1.32 & 0.99 \\
\hline & Bias & & 0.55 & 0.64 & -0.03 \\
\hline
\end{tabular}




\section{List of figures}

Fig 1. Run-up on bermed slopes

Fig 2. (a) Schematic cross section of the tested model and b) Experimental set-up

Fig 3. Comparison between $R *_{\text {meas }}$ and $R *_{\text {est }}$ using the formulas of (a) Ahrens and Ward [6] (b) Van der Meer et al. [2] and c) This study

Fig 4. Comparison between $R *_{\text {meas }}$ and $R *_{\text {est }}$ using different formulas, field data 


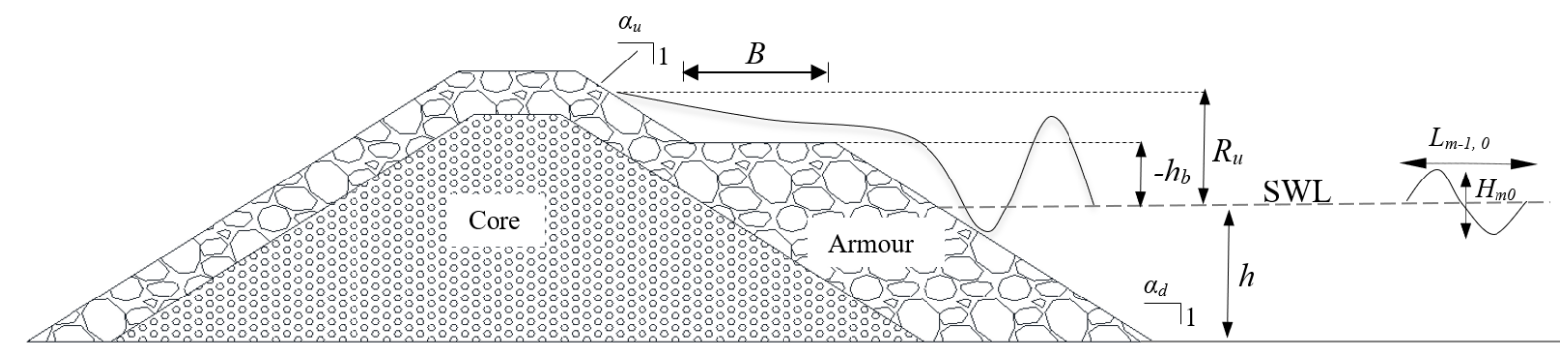

Fig 1. Run-up on bermed slopes 


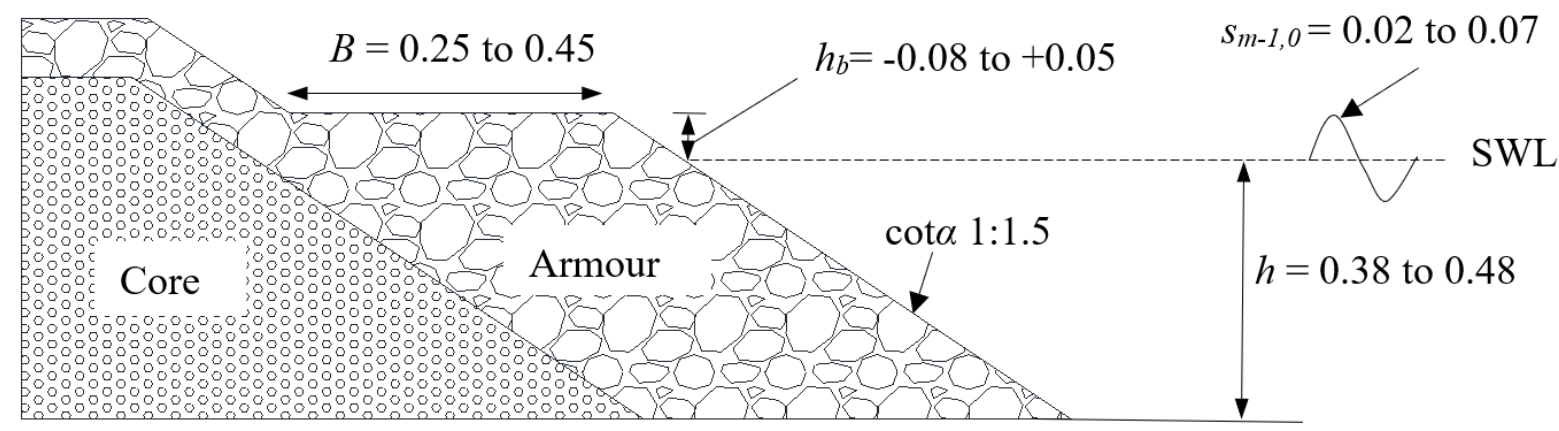

(a)

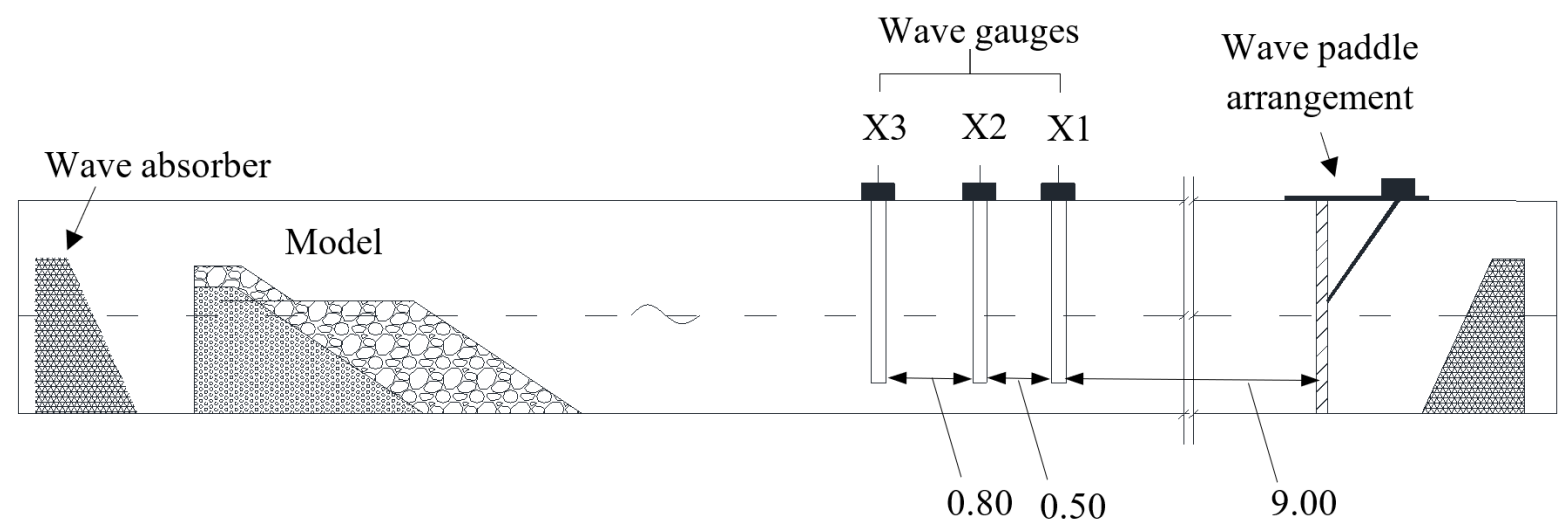

(c)

(All dimensions in metres)

Fig.2 (a) Schematic cross section of the tested model and b) Experimental set-up 


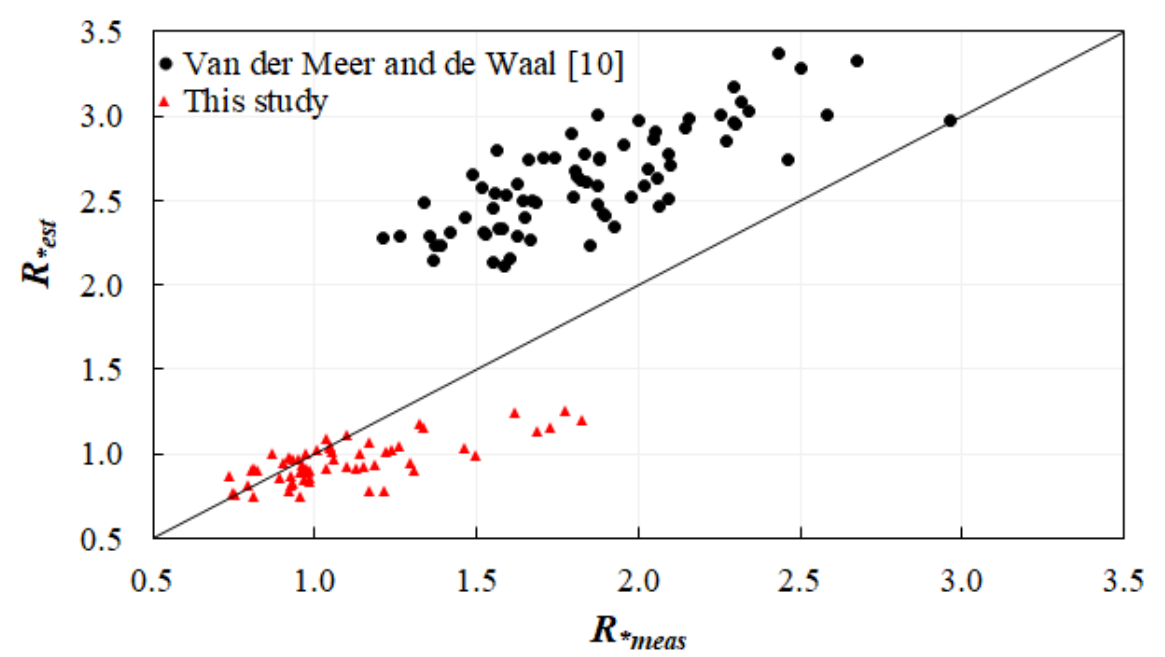

(a)

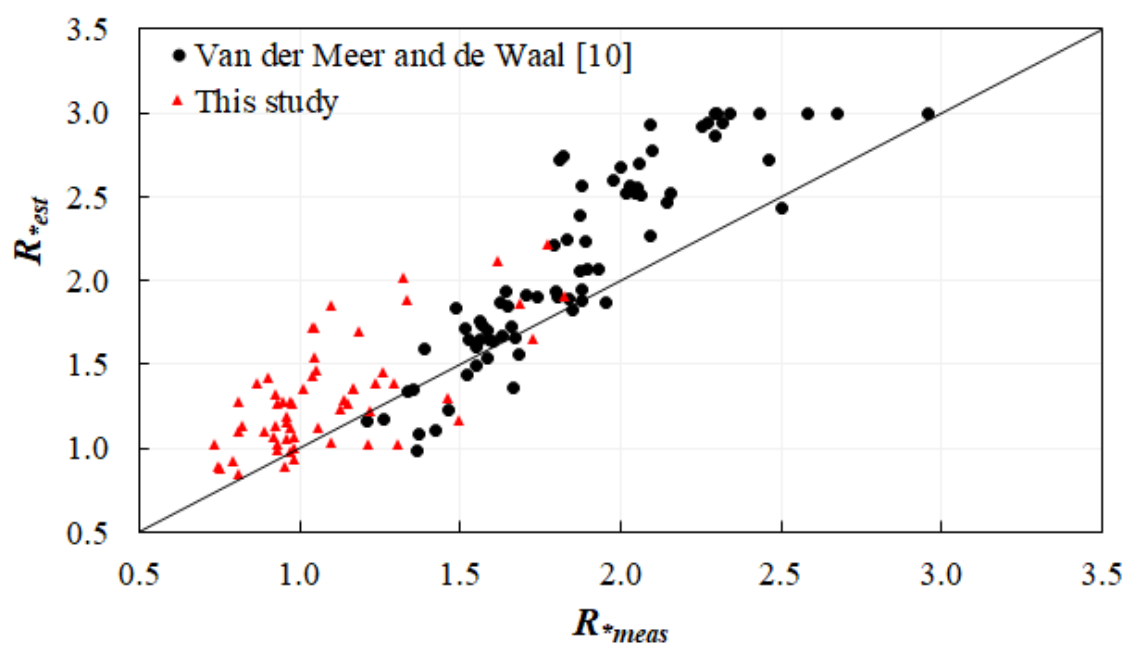

(b)

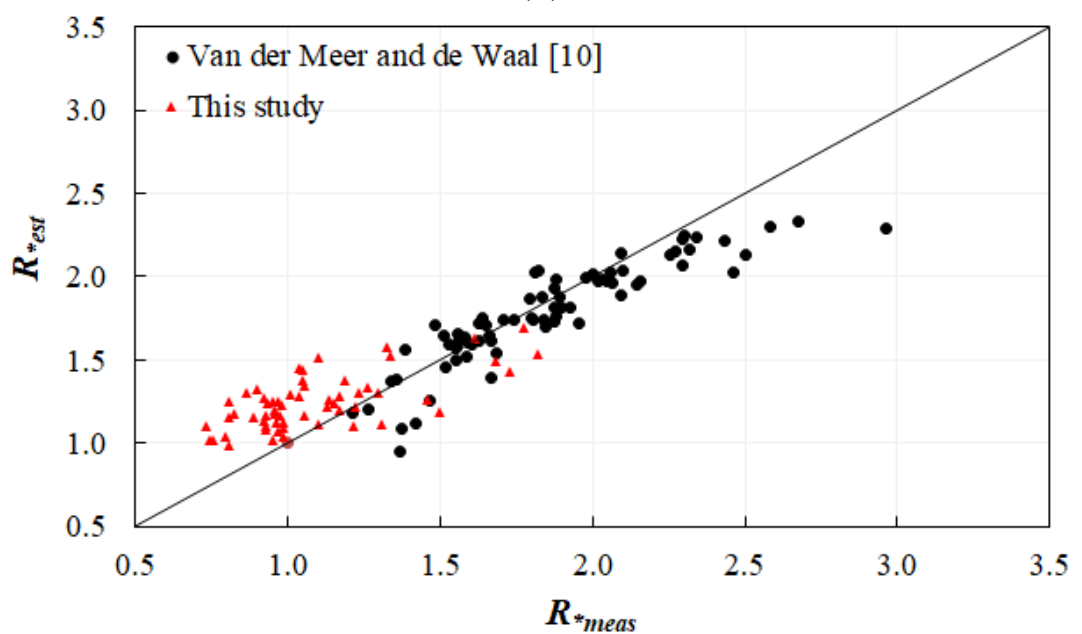

(c)

Fig 3. Comparison between $R *_{\text {meas }}$ and $R *_{\text {est }}$ using the formula of (a) Modified Ahrens and

Ward [6] (b) Van der Meer et al. [2] and c) This study. The solid lines are the optimal line (45 degree). 


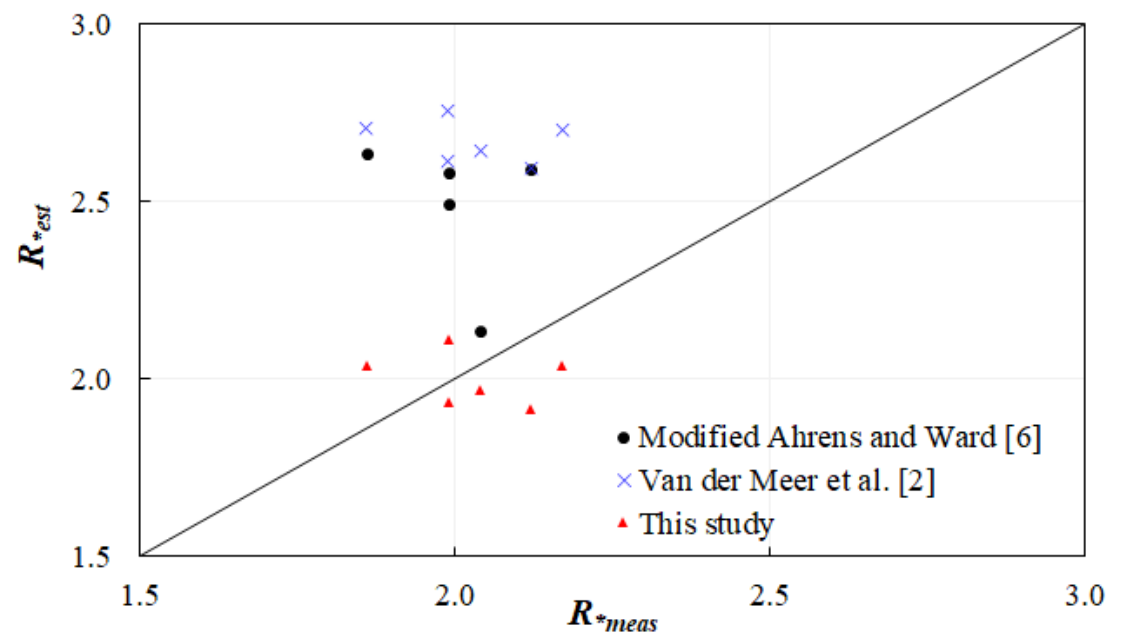

Fig 4. Comparison between $R *_{\text {meas }}$ and $R *_{\text {est }}$ using different formulas, field data. The solid line is the optimal line (45 degree). 


\section{Appendix A - M5}

M5 model tree is a data mining technique implemented through the WEKA software [20]. M5 has been used in coastal engineering to predict the armour stability [21] and overtopping discharge [22] at rubble mound breakwaters, wave height prediction in Lake Superior [23], to develop the wave spectrum at the Gulf of Maine: USA and Bay of Bengal: India [24], estimation of wind speed from wave measurements [25], to develop an improved overtopping prediction model for inclined coastal structures with smooth impermeable surface [26] and vertical structures [27]. The details of M5 technique can be obtained from Quinlan [28] and Wang and Witten [14], the excerpt of which are enumerated below.

M5 is the algorithm used to develop the model tree and it has three stages 1) building the tree 2) pruning and 3) smoothing which leads to prediction of introduced data. The MT developed by M5 algorithm is similar to an inverted tree where the data is fed into the root and the related prediction of the introduced data is obtained from leaves. M5 algorithm splits the input data recursively into subsets. The splitting is monitored in such a way that the Standard Deviation Reduction (SDR) factor (Eq. A.1) is minimum between subsets. The SDR is estimated for every sub-space obtained as a result of the splitting process and it is compared with the data space before splitting. The splitting process is stopped when the SDR is less than $5 \%$, or only a few data remain. A linear regression model is then developed for the data associated with each leaf.

$$
\mathrm{SDR}=\frac{M}{|T|} \operatorname{sd}(T)-\sum \frac{\left|T_{i}\right|}{|T|} \times \operatorname{sd}\left(T_{i}\right)
$$

In the pruning stage, the developed linear model is multiplied with a factor $(n+v) /(n-v)$ to minimise the errors due to overfitting due to growth of the model tree. Here, $n$ is the number of training data points that reach the node and $v$ is the number of input parameters in the model that represent the output value at that node. The discontinuities between adjacent 
linear models (pruned leaves) are regularised in the smoothing stage. Thus, the M5 algorithm produces a set of linear multi-variable equations. 


\section{Appendix B - Worked example for estimation of wave run up}

In this section, an example for the estimation of wave run up using the developed formula (Eq. 17) for the design conditions of Sirevag berm breakwater [29] is presented. The design conditions and calculation details for the estimation of $R_{u 2} \% H_{m 0}$ using the formula developed in this study are listed below.

Design conditions: $H_{m 0}=7.0 \mathrm{~m}, T_{m-1,0}=9.64 \mathrm{~s}, h=17.5 \mathrm{~m}, \cot \alpha=1.5, B=19.7 \mathrm{~m}$ and $h_{b}=-$ $6.4 \mathrm{~m}$.

$S_{m-1,0}=\frac{2 \pi H_{m 0}}{g T_{m-1,0}^{2}}: S_{0 m-1,0}=0.048$ (Eq. 9)

$L_{b e r m}=B+\left(1 H_{m 0}+h_{b}\right) \cot \alpha_{u}+\left(1 H_{m 0}-h_{b}\right) \cot \alpha_{d}=40.7 \mathrm{~m}$

$r_{B}=\frac{B}{L_{\text {berm }}}: r_{B}=0.48($ Eq. 13)

$r_{h b}=0.5-0.5 \cos \left(\pi \frac{h_{b}}{R_{u 2 \%}}\right): r_{h b}=0.67$ (Eq. 14 , Here $R_{u 2 \%}$ is assumed as $1.5 H_{m 0}$ )

$\gamma_{b}=1-r_{B}\left(1-r_{h b}\right) \geq 0.6: \gamma_{b}=0.84($ Eq. 12)

$\gamma_{h}=1-0.03\left(4-\frac{h}{H_{m 0}}\right)^{2}: \gamma_{h}=0.93($ Eq. 15$)$

Berm breakwater and head on waves: $\gamma_{f}=0.40$ and $\gamma_{\beta}=1.0$

$L_{s}=B+\left[\left(1.5 H_{m 0}+h_{b}\right) \cot \alpha_{u}\right]+\left[\left(1.5 H_{m 0}-h_{b}\right) \cot \alpha_{d}\right]: L_{s}=51.2 \mathrm{~m}($ Eq. 8$)$

$\tan \alpha_{a v}=\frac{3 H_{m 0}}{L_{s}-B}: \tan _{\alpha a v}=0.67($ Eq. 7)

$\xi_{m-1,0}=\frac{\tan \alpha_{a v}}{\sqrt{s_{m-1,0}}}: \xi_{m-1,0}=3.033($ Eq. 6) 


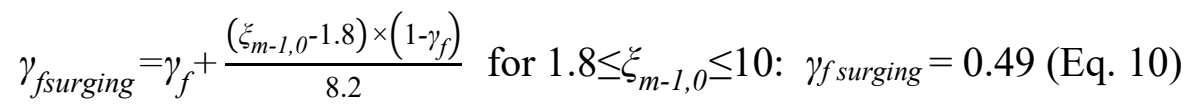

$1.0 \gamma_{\text {fsurging }} \gamma_{\beta}\left(3.15-\frac{1.5}{\gamma_{b} \xi_{m-1,0}}\right):$ Maximum $R *=1.26$ (Eq. 17)

$R *=\frac{R_{u 2 \%}}{H_{m 0}}=7.7 \gamma_{b} \gamma_{h} \gamma_{f} \gamma_{\beta}\left[1-\exp \left(-0.78 \xi_{m-1,0}\right)\right]<1.26: R *=1.26($ Eq. 16)

$R_{u 2 \%}=1.26 \times 7=8.82 \mathrm{~m}$

(Using the Van der Meer et al. [2] formula (Eqs. 4 and 5) and the modified Ahrens and Ward [6] formula (Eq. 3), the $R *$ values are 1.68 and 1.13, respectively.) 


\section{References}

[1] S.A. Hughes, Estimation of wave run-up on smooth, impermeable slopes using the wave momentum flux parameter, Coast. Eng. 51 (2004) 1085-1104.

[2] EurOtop Manual on wave overtopping of sea defences and related structures. An overtopping manual largely based on European research, but for worldwide application. Van der Meer, J.W., Allsop, N.W.H., Bruce, T., De Rouck, J., Kortenhaus, A., Pullen, T., Schüttrumpf, H., Troch, P. and Zanuttigh, B., (2016 ). www.overtopping-manual.com.

[3] A.I .Diwedar, Investigating the effect of wave parameters on wave runup, Alex. Eng. J. 55 (2015) 627-633.

[4] K. Pillai, A. Etemad-Shahidi, C. Lemckert, Wave overtopping at berm breakwaters: Review and sensitivity analysis of prediction models, Coast. Eng. 120 (2017) 1-21.

[5] K. Pillai, A. Etemad-Shahidi, C. Lemckert, Wave overtopping at berm breakwaters: Experimental study and development of prediction formula, Coast. Eng. 130 (2017) 85-102.

[6] J.P. Ahrens, D.L. Ward, Performance of bermed revetments, J. of Waterw. Port Coast. and Ocean Eng. 117(5) (1991) 534-540.

[7] D.L. Ward, J.P. Ahrens, Use of rubble berm for reducing runup and overtopping on a 1v to $2 \mathrm{~h}$ riprap slope; experimental model investigation, Report number: REMR-CO-17, 1990.

[8] J.W. Van der Meer, Rock slopes and gravel beaches under wave attack, PhD Thesis, Delft University of Technology, Netherlands, 1988.

[9] J.W. Van der Meer, J.P.F.M. Janssen, Wave run up and wave overtopping at dikes and revetments, Report number: 485, Deft Hydraulics, 1994. 
[10] J.W. Van der Meer, J.P. De Waal, Waterbeweging op taluds. Invloed van berm. Ruwheid. Ondiep voorland en scheve lang- en kortkammige golfaanval. "Water movement on slopes". Intluence of berm roughness shallow foreshore and oblique and short-crested wave attack, Report on model investigation, Delft Hydraulics, 1993.

[11] J.C. Krom, Wave overtopping at rubble mound breakwaters with a non-reshaping berm, Master Thesis, Department of Civil Engineering, Delft University of Technology, Netherlands, 2012.

[12] A. Etemad-Shahidi, M. Bali, Stability of rubble-mound breakwater using $H_{50}$ wave height parameter, Coast. Eng. 59(1) (2012) 38-45.

[13] E.P.D. Mansard, E.R. Funke, The measurement of incident and reflected spectra using a least squares method, Proc. of the 17th Coastal Engineering Conf. Sydney, Australia, (1980) 154-172.

[14] Y. Wang, I.H. Witten, Induction of model trees for predicting continuous classes, Proc. of the Poster Papers of the European Conf. on Machine Learning, Prague, 1997

[15] L. Bonakdar, A. Etemad-Shahidi, Predicting wave run-up on rubble-mound structures using M5 model tree, Ocean Eng. 38(1) (2011) 111-118.

[16] M.R.A. Van Gent, Wave runup on dikes with shallow foreshores, J. of Waterw. Port Coast. and Ocean Eng. 127(5) (2001) 254-262.

[17] H. Verhaeghe, Neural Network Prediction of Wave Overtopping at Coastal Structure, PhD Thesis, Ghent University, 2005.

[18] H. Verhaeghe, J. de Rouck, J.W. Van Der Meer, Combined classifier-quantifiermodel: A 2-phases neural model for prediction of wave overtopping at coastal structures, Coast. Eng. 55 (2008) 357-374. 
[19] R. Yasa, A. Etemad-Shahidi, Classification and regression trees approach for predicting current-induced scour depth under pipelines, J. of Offshore Mechanics and Arctic Eng. 136(1) (2014).

[20] E. Frank, M.A. Hall, I.H. Witten, The WEKA Workbench. Online Appendix for Data Mining: Practical Machine Learning Tools and Techniques, Fourth ed. Morgan, 2016.

[21] A. Etemad-Shahidi, L. Bonakdar, Design of rubble-mound breakwaters using M5 machine learning method, Appl. Ocean Res. 31 (3) (2009) 197 - 201.

[22] E. Jafari, A. Etemad-Shahidi, Derivation of a new model for prediction of wave overtopping at rubble mound structures, J. Waterw. Port. Coast. Ocean. Eng. 138 (1) (2012) 42-52.

[23] A. Etemad-Shahidi, J. Mahjoobi, Comparison between M5 model tree and neural networks for prediction of significant wave height in Lake Superior. Ocean Eng. 36 $(15-16)(2009) 1175-1181$.

[24] S. Sakhare, M.C. Deo, Derivation of wave spectrum using data driven methods, Marine Structures 22 (3) (2009) 594 - 609.

[25] M. Daga, M.C. Deo, Alternative data-driven methods to estimate wind from waves by inverse modeling, Nat. Hazards 49 (2) (2009) 293 -310.

[26] A. Etemad-Shahidi, E. Jafari, E, New formulae for prediction of wave overtopping at inclined structures with smooth impermeable surface, Ocean Eng. 84 (2014) 124 132.

[27] A. Etemad-Shahidi, S. Shaeri, E. Jafari, Prediction of wave overtopping at vertical structures, Coast. Eng. 109 (2016), 42 - 52.

[28] J.R. Quinlan, Learning with Continuous Classes. World Scientific,1992.

[29] A. Torum, F. Kuhnen, A. Menze, On berm breakwaters. Stability, scour, overtopping. J. of Coast. Eng. 49 (3) (2003) 209 - 238. 